\title{
Group decision rules and group rationality under risk
}

\author{
Aurélien Baillon ${ }^{1} \cdot$ Han Bleichrodt ${ }^{1} \cdot$ Ning Liu $^{1}$. \\ Peter P. Wakker ${ }^{1}$
}

Published online: 15 June 2016

C The Author(s) 2016. This article is published with open access at Springerlink.com

\begin{abstract}
This paper investigates the rationality of group decisions versus individual decisions under risk. We study two group decision rules, majority and unanimity, in stochastic dominance and Allais paradox tasks. We distinguish communication effects (the effects of group discussions and interactions) from aggregation effects (mere impact of the voting procedure), which makes it possible to better understand the complex dynamics of group decision making. In an experiment, both effects occurred for intellective tasks whereas there were only aggregation effects in judgmental tasks. Communication effects always led to more rational choices; aggregation effects did so sometimes but not always. Groups violated stochastic dominance less often than individuals did, which was due to both aggregation and communication effects. In the Allais paradox tasks, there were almost no communication effects, and aggregation effects made groups deviate more from expected utility than individuals.
\end{abstract}

Keywords Group decisions under risk - Unanimity rule $\cdot$ Majority rule $\cdot$ Allais paradox

JEL Classification D81 C C91

Many economic decisions - e.g. family financial planning, corporate strategies, national laws - are made by groups. The literature comparing individual and group decision making is rich (Kugler et al. 2012). Groups have been found to attenuate, amplify, or replicate the biases found for individual decisions (Kerr et al. 1996), and these diverse findings highlight the closing remark of a recent review paper: "Ultimately, the goal of

Electronic supplementary material The online version of this article (doi:10.1007/s11166-016-9237-8) contains supplementary material, which is available to authorized users.

Peter P. Wakker

Wakker@ese.eur.nl

1 Erasmus School of Economics, Erasmus University Rotterdam, Rotterdam, The Netherlands 
comparing individual and group decision making is to identify the contexts and types of decisions where each is likely to work best" (Charness and Sutter 2012, p. 174).

This paper compares group and individual decision making for three tasks: a test of non-transparent stochastic dominance, the Allais common consequence paradox, and the Allais common ratio paradox. Stochastic dominance is an objective, generally accepted criterion of rationality but recognizing it may require intellectual effort. We will therefore refer to this type of task as intellective. Previous research has shown that groups violate stochastic dominance less frequently than individuals (Charness et al. 2007), suggesting that group decisions improve rationality. Expected utility (EU) violations are to a large extent due to motivational or subjective aspects of human behavior. We will, therefore, call the Allais tasks judgmental. In this, we follow the psychological literature on group decisions (e.g. Laughlin and Ellis 1986; Kerr and Tindale 2011), where problems with a demonstrably correct answer are called intellective and tasks in which one cannot objectively defend one's preferred alternative as correct (e.g. aesthetic judgments or matters of personal taste) are called judgmental. In Allais' common consequence and common ratio paradoxes (Allais 1953), previous research has found that groups violate EU as often as individuals do (Rockenbach et al. 2007; Bone et al. 1999; Bateman and Munro 2005).

We distinguish two components in group decision making: aggregation and communication. Aggregation refers to the direct effect of the procedure on the group decision, without involving any change of an individual or any communication. In single choice tasks, aggregation effects tend to amplify the patterns exhibited by the majority, as we will show; these effects are merely procedural and statistical. For tasks involving two choices (as in the Allais paradoxes), however, aggregation effects can reverse the majority pattern. It then is, for example, possible that, while a majority of the group members behave according to EU, the group decision violates EU. Aggregation effects are fleeting and do not influence individual attitudes or subsequent individual decisions.

Communication effects do influence individuals. Communication effects are lasting and capture the effects of group decision making beyond pure aggregation. These effects include the impact of learning what others prefer and why they prefer it. For instance, group decision making can foster discussion and this may change members' preferences. Communication effects will persist after the group process has ended (Maciejovsky et al. 2013).

In our experiment, we measured the strength of aggregation and communication effects for majority and unanimity group decisions. We elicited individual preferences before and after the group decision stage. Changes in individual preferences were interpreted as communication effects. We also used a second approach to measure communication effects. To control for the effect of aggregation, we aggregated the individual decisions before the group decision stage into simulated group decisions. Differences between these simulated decisions and the actual group decisions constitute communication effects. For instance, in the actual group decisions a minority sometimes convinced a majority to change their preferences, which was clearly a communication effect.

The effects of decision rules are central in political economics (Feddersen and Pesendorfer 1998; Messner and Polborn 2004), and have also been studied in psychology (Kerr and Tindale 2004). However, they have rarely been considered for decisions 
under risk. An exception is Brunette et al. (2015), who implemented majority and unanimity voting rules, but did not permit verbal communication between group members. Most existing studies considered groups of two individuals, for which majority and unanimity rules make the same predictions and therefore cannot be distinguished. We used groups of three individuals, for which these rules can be distinguished. In intellective tasks, the results indicated that both rules led to aggregation and communication effects, which improved both group rationality and individual rationality. In the judgmental tasks there were mainly aggregation effects, which led to more deviations from expected utility for groups than for individuals in one of the tasks (the common ratio task).

\section{Literature}

According to social-decision scheme theory (Davis 1973), group decisions are determined by the majority view unless the minority view is demonstrably correct, which is the case where "truth wins" (Laughlin and Ellis 1986; Davis 1992; Kerr and Tindale 2011). This suggests that communication effects will be stronger when the reasons for choosing one option are easy to defend. Because answers in intellective tasks are easier to defend than answers in judgmental tasks, we expect that communication effects will be stronger in the non-transparent stochastic dominance (NTSD) tasks than in the Allais tasks.

The literature on group decision processes shows that the unanimity rule typically leads to more communication than the majority rule. Moreover, group members identify themselves more with unanimous decisions than with majority decisions (Kameda 1991). The deliberations of unanimity groups show more conflicts and more changes of opinion (Nemeth 1977). Accordingly, we hypothesize that the unanimity rule leads to more discussion than the majority rule and, consequently, to stronger communication effects.

Several studies have investigated the effect of different aggregation rules on the outcome of the decision process, both theoretically and experimentally. Dasgupta and Maskin (2008) showed theoretically that the majority rule satisfies five appealing conditions (Pareto optimality, anonymity, neutrality, independence of irrelevant alternatives, and decisiveness) over a larger class of preferences than any other voting rule does and, in this sense, is the most robust rule.

For jury decision making, Feddersen and Pesendorfer (1998) showed theoretically that the unanimity rule is more likely to convict the innocent and to acquit the guilty if jury members vote strategically. However, Goeree and Yariv (2011) found in an experiment that such differences in jury decisions vanish when deliberation before voting is allowed. Miller (1985) and Ohtsubo et al. (2004) showed experimentally that majority group decisions tend to ignore the minority's preferences whereas the unanimity decisions incorporate the minority's preferences when information about each group member's preference is available. Finally, Stasson et al. (1991) showed that subjects from majority groups performed marginally better than subjects from unanimity groups in mathematical tasks. However, groups consisting only of members who had answered incorrectly in the individual tasks were more likely to find the correct solution under the unanimity rule. 


\section{Examples of aggregation effects}

To clarify the role of aggregation and to show how it can distort group decisions, we give two simple examples, one involving a single choice (as in the NTSD task) and one involving two choices (as in the Allais paradoxes). A similar aggregation effect was discussed by Evans (1997) in a market context.

\section{Example 1: Aggregation effects in a single choice}

Consider a choice between two lotteries where one lottery stochastically dominates the other. Assume that a minority of the population violates stochastic dominance. If people in this population form groups and the group choice is made by the majority rule, then sufficiently large groups will almost always satisfy stochastic dominance. Aggregation effects amplify the majority choice, and provided the majority is rational, will amplify rationality. This results purely from the aggregation procedure, without involving any change of any person or any communication.

\section{Example 2: Aggregation effects in a pair of choices}

Aggregation effects are more complex when two choices have to be made as in the Allais paradoxes. Consider two choices, each between a risky lottery $\mathrm{R}$ and a safe lottery S. Then there are four possible choice patterns: SS, RR, SR, and RS. The SS and RR patterns are consistent with EU (EU-consistent), and the SR and RS patterns are EU-inconsistent.

Suppose that $30 \%$ of the sample chooses SS, $30 \%$ chooses RR, and $40 \%$ chooses SR. Then the majority of the population (60\%) is EU-consistent. If we randomly draw groups of three persons from this population and let the group choice be determined by majority then SR will be chosen in $56.8 \%$ of the cases and the majority thus exhibits an EU-inconsistent pattern. The opposite case (a majority of EU-inconsistent people leading to a majority of EU-consistent groups) can also occur. ${ }^{1}$ Again, this results purely from the aggregation procedure.

\section{Method}

\subsection{Experimental design}

$N=156$ students of Erasmus University Rotterdam participated in the experiment (63\% males). We organized 52 sessions of three subjects each.

The experiment consisted of three stages (within-subjects) and three treatments (between-subjects; see Table 1). A stage consisted of a set of instructions and decision tasks, which subjects received on paper (called answer sheets hereafter). All decision tasks were choices between two lotteries. The subjects in a session each had their own colored pen (blue, red, or black) to mark their preferred lottery on the answer sheet so that we could identify individual choices.

\footnotetext{
${ }^{1}$ If the individuals exhibit patterns SS, RR, SR, and RS with probability $40 \%, 0 \%, 30 \%$, and $30 \%$ respectively, then the groups will exhibit the same patterns with probability $56.8 \%, 0 \%, 21.6 \%$, and $21.6 \%$.
} 
Table 1 Structure of the experiment

\begin{tabular}{llll}
\hline & Stage 1 & Stage 2 & Stage 3 \\
\hline Control & Individual & Individual & Individual \\
M-treatment & Individual & Majority rule & Individual \\
U-treatment & Individual & Unanimity rule & Individual \\
\hline
\end{tabular}

In the first and third stages of the experiment, subjects made individual choices and were not allowed to talk with each other. Only the second stage of the experiment differed between treatments. In the control treatment, subjects made individual decisions (without communication), as in the other two stages. This permitted us to check for any learning effect. In the M-treatment, the three subjects in a session made group decisions using the majority rule and they could communicate face-to-face in English. All subjects, after (possible) discussion, marked their preferred lotteries. The option with at least two ticks was taken as the group choice, but minority subjects could still express disagreement. In the U-treatment subjects had to reach unanimity. All three subjects of a session had to tick the same lottery, otherwise the choice was invalid and would not be paid (see the section on incentives below). The groups of the U-treatment always reached unanimity. Subjects could freely and directly communicate during the group decisions (stage 2 of M- and U-treatment). In the control treatment, answering all questions took 21 minutes on average. In the other two treatments, subjects needed about 7 minutes more due to group deliberations.

Stage 1 gave us information on subjects' behavior before any treatment manipulation. We used these choices to simulate the group decisions that would have been made based on the majority rule and, thereby, we inferred the effect of pure aggregation without any communication. We could then compare the actual group decisions in stage 2 with these simulated decisions to measure the effects beyond pure aggregation. Finally, stage 3 gave information about whether any changes in preferences that we observed in stage 2 were temporary (and thus probably due to aggregation effects) or lasting (which is likely for communication effects).

Each session of three subjects was randomly assigned to one treatment. We ran 13 sessions for the control treatment, 21 sessions for the M-treatment, and 18 sessions for the U-treatment. There were fewer sessions of the control treatments to have more observations in $\mathrm{M}$ - and U-treatments, which concerned the main research questions.

\subsection{Stimuli}

Subjects faced three types of decision tasks in each stage of the experiment: NTSD tasks, common ratio (CR) tasks, and common consequence (CC) tasks. We present these tasks below. The order of the choices was randomized within each of the three stages (it was therefore possible that two questions for the same CR task were far apart in the experiment), but the order was the same for all subjects within a particular treatment. Huber et al. (2008) showed that choices are affected by the first and the last choice made. No distortions result when there are no more than three choices, as in our experiment.

Subjects had to choose between two lotteries, A and B. Table 2 gives an example of the way choices were displayed. Uncertainty was resolved using the roll of a 20 -sided 
Table 2 An NTSD task

\begin{tabular}{|c|c|c|c|c|c|c|c|c|c|c|c|c|c|c|c|c|c|c|c|c|}
\hline & 1 & 2 & 3 & 4 & 5 & 6 & 7 & 8 & 9 & 10 & 11 & 12 & 13 & 14 & 15 & 16 & 17 & 18 & 19 & 20 \\
\hline Lottery A & \multicolumn{12}{|c|}{$€ 0$} & \multicolumn{4}{|c|}{$€ 35$} & $€ 30$ & \multicolumn{3}{|l|}{$€ 5$} \\
\hline Lottery B & $€ 5$ & $€ 1$ & & $€ 3$ & & & & & $€ 0$ & & & & & & & & & & & \\
\hline
\end{tabular}

die. The first row of Table 2 shows the possible outcomes of the roll of the die. Rows 2 and 3 show the payoffs of the two lotteries under each possible roll of the die. Subjects indicated their choice by ticking the cell of the last column of their preferred lottery.

\subsubsection{NTSD tasks}

Charness et al. (2007) found that groups are more likely to satisfy stochastic dominance than individuals, but did not specify the aggregation rule that groups should follow and did not check whether the group effects persisted in later individual choices. Maciejovsky et al. (2013) found that group effects persisted in intellective tasks other than NTSD, but they did not distinguish between the majority rule and the unanimity rule as their group size was two people, for which the two rules lead to the same results. We adapted the NTSD tasks first used by Tversky and Kahneman (1986).

Table 2 is an example of an NTSD task faced by the subjects. Lottery B results from lottery A by improving $€ 30$ into $€ 35$ and by improving two outcomes $€ 5$ into $€ 10$. Consequently, lottery B stochastically dominates lottery A. However, this dominance is not immediately obvious and a subject who neglects probability differences and only compares the outcomes of the lotteries may have the false impression that $\mathrm{A}$ is better than $\mathrm{B}$ because it yields money amounts $€ 5, € 30$, and $€ 35$, whereas Lottery B yields money amounts $€ 5, € 10$, and $€ 35$. Because the violation of stochastic dominance in Table 2 is non-transparent, we refer to these tasks as NTSD. Some theories allow for such violations of stochastic dominance (Kahneman and Tversky 1979; Viscusi 1989). Table 3 summarizes the tests of non-transparent stochastic dominance that we carried out. The tests are comparable in structure but differ across the three stages.

Table 3 NTSD questions

\begin{tabular}{|c|c|c|c|c|c|c|c|c|}
\hline & \multicolumn{4}{|c|}{ Dominated lottery } & \multicolumn{4}{|c|}{ Dominant lottery } \\
\hline & $20 \%$ & $5 \%$ & $15 \%$ & $60 \%$ & $25 \%$ & $10 \%$ & $5 \%$ & $60 \%$ \\
\hline \multirow{5}{*}{ Stage 1} & 35 & 30 & 5 & 0 & 5 & 10 & 35 & 0 \\
\hline & 40 & 30 & 8 & 0 & 8 & 12 & 40 & 0 \\
\hline & 40 & 35 & 5 & 0 & 5 & 10 & 40 & 0 \\
\hline & 45 & 40 & 10 & 0 & 10 & 15 & 45 & 0 \\
\hline & 35 & 28 & 5 & 0 & 5 & 10 & 35 & 0 \\
\hline \multirow{5}{*}{ Stage 2} & 35 & 32 & 8 & 0 & 8 & 12 & 35 & 0 \\
\hline & 35 & 30 & 8 & 0 & 8 & 12 & 35 & 0 \\
\hline & 45 & 35 & 5 & 0 & 5 & 10 & 45 & 0 \\
\hline & 40 & 35 & 10 & 0 & 10 & 15 & 40 & 0 \\
\hline & 45 & 28 & 8 & 0 & 8 & 12 & 45 & 0 \\
\hline \multirow{5}{*}{ Stage 3} & 40 & 28 & 5 & 0 & 5 & 12 & 40 & 0 \\
\hline & 45 & 30 & 8 & 0 & 8 & 15 & 45 & 0 \\
\hline & 45 & 25 & 10 & 0 & 10 & 15 & 45 & 0 \\
\hline & 40 & 25 & 5 & 0 & 5 & 10 & 40 & 0 \\
\hline & 35 & 30 & 8 & 0 & 8 & 12 & 35 & 0 \\
\hline
\end{tabular}

The second row indicates the probabilities of the outcomes. The numbers below the probabilities indicate payoffs in $€$ 
Table 4 A CC task

a) First choice

\begin{tabular}{|c|c|c|c|c|c|c|c|c|c|c|c|c|c|c|c|c|c|c|c|c|}
\hline & 1 & 2 & 3 & 4 & 5 & 6 & 7 & 8 & 9 & 10 & 11 & 12 & 13 & 14 & 15 & 16 & 17 & 18 & 19 & 20 \\
\hline Lottery $S$ & \multicolumn{20}{|c|}{$€ s$} \\
\hline Lottery $R$ & & $€$ & & & & & & & & & $€ s$ & & & & & & & & $r$ & \\
\hline
\end{tabular}

b) Second choice

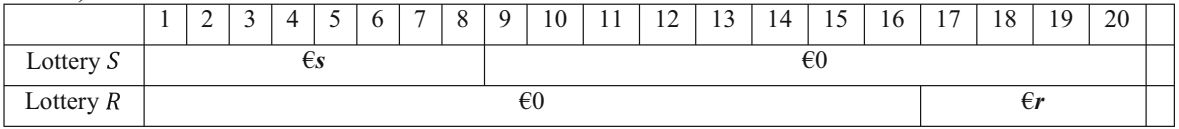

Actual payoffs $s$ and $r$ are in Table 5. In the experiment, lotteries were presented as Lottery A and Lottery B

Table 5 Payoffs and common probability of the CC tasks

\begin{tabular}{l|rrrr|rrr|rrr} 
& \multicolumn{5}{|c|}{ Stage 1 } & \multicolumn{3}{c|}{ Stage 2 } & \multicolumn{3}{c}{ Stage 3 } \\
\hline $\boldsymbol{s}$ & 8 & 8 & 9 & 8 & 10 & 9 & 10 & 10 & 8 & 10 \\
$\boldsymbol{r}$ & 25 & 25 & 30 & 20 & 45 & 30 & 45 & 40 & 20 & 40 \\
$\boldsymbol{q}$ & $60 \%$ & $55 \%$ & $55 \%$ & $55 \%$ & $60 \%$ & $60 \%$ & $55 \%$ & $60 \%$ & $60 \%$ & $55 \%$ \\
\hline
\end{tabular}

The first column means that in Table 4, we used $s=€ 8, r=€ 25$, and $q=60 \%$. The first choice was therefore between a lottery $S$ yielding $€ 8$ for sure and a lottery R yielding $€ 25$ with probability $20 \%, € 8$ with probability $60 \%$ and $€ 0$ otherwise. The second choice involved lottery S, yielding $€ 8$ with probability $40 \%(=100 \%-q)$ and nothing otherwise, and lottery R yielding $€ 25$ with probability $20 \%$ and nothing otherwise

\subsubsection{CC tasks}

The CC tasks were close to those of Huck and Müller (2012) with a small adjustment to fit into our 20-sided die format.

Table 4 shows the structure of the CC tasks. Table 5 presents the different values of $s, r$, and $q$ that we used in the experiment. ${ }^{2}$ Each CC task involved two choices between lottery $\mathrm{S}$ and lottery $\mathrm{R}$ with the second choice similar to the first except that the (common) $q$ chance (60\% in the above example) of $€ \mathrm{~s}$ was changed into a $q$ chance of nothing.

According to the sure-thing principle of EU (Savage 1954), replacing a common payoff by another common payoff does not affect preference. Hence EU predicts the same preference in both choices, either SS or RR. However, empirically, many subjects violate EU and display the pattern SR, which can be due to the certainty effect (see Starmer 2000 for a survey). The opposite pattern, RS, occurs less frequently (Starmer 1992; Wu et al. 2005; Blavatskyy 2013).

\subsubsection{CR tasks}

The CR questions were adapted from Loomes (1988), using the design of van de Kuilen and Wakker (2006).

Table 6 shows the way the CR choices were presented to the subjects. The second choice follows from the first by dividing all probabilities at nonzero outcomes by 4 . According to the independence condition of EU (Fishburn and Wakker 1995), this should not affect preferences. Hence EU predicts the same choice in both situations, either SS or RR. However, empirically, the prevailing pattern is SR, which violates EU. The opposite violation, RS, occurs rarely. Table 7 presents the values used.

\footnotetext{
$\overline{2}$ Stage 1 had four CC tasks and stages 2 and 3 had three CC tasks.
} 
Table 6 A CR task

a) First choice

\begin{tabular}{|c|c|c|c|c|c|c|c|c|c|c|c|c|c|c|c|c|c|c|c|}
\hline & 1 & 2 & 3 & 4 & 5 & 6 & 7 & 8 & 10 & 11 & 12 & 13 & 14 & 15 & 16 & 17 & 18 & 19 & 20 \\
\hline Lottery $\mathrm{S}$ & \multicolumn{19}{|c|}{$€ s$} \\
\hline Lottery R & & & & & & & & & $€ r$ & & & & & & & & & & \\
\hline
\end{tabular}

b) Second choice

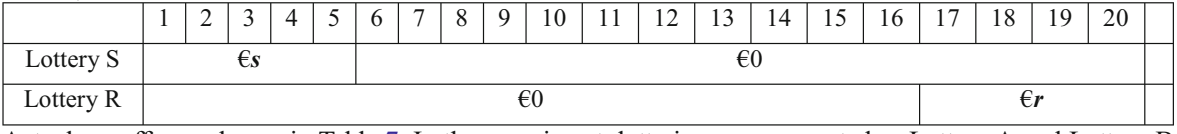

Actual payoffs s and $\mathrm{r}$ are in Table 7. In the experiment, lotteries were presented as Lottery A and Lottery B

Table 7 Payoffs of the CR tasks

\begin{tabular}{l|lllll|llllll|lllll} 
& \multicolumn{1}{|l}{ Stage 1 } & \multicolumn{1}{l|}{ Stage 2} & \multicolumn{1}{l|}{ Stage 3 } \\
\hline $\boldsymbol{s}$ & 18 & 9 & 14 & 10.5 & 20 & 16.5 & 15 & 9.5 & 11.5 & 12.5 & 13 & 10 & 15.5 & 17.5 & 19 \\
$\boldsymbol{r}$ & 24.5 & 12 & 18 & 14.5 & 25.5 & 22.5 & 20.5 & 13 & 15 & 17.5 & 18 & 14 & 21.5 & 24 & 25 \\
\hline
\end{tabular}

\subsubsection{Incentives}

Upon completion of the experiment, subjects received a $€ 5$ participation fee. In addition, they played out one of their choices for real. First, one of the three stages was randomly selected. All subjects in a session played out a choice that was made in this stage. If the selected stage was an individual stage (stages 1 and 3 for the $\mathrm{M}$ - and $\mathrm{U}$ treatments, and all stages for the control treatment), each subject randomly drew one choice and played out the lottery he preferred in that choice.

If the second stage was selected in the M- and U-treatments, the lottery the group had chosen was played out and the three subjects received the same payoff. In the group decision making stage, subjects shared the consequences of their choice. We explained this group incentive procedure in the M- and U-treatments at the beginning of stage 2 . The instructions were the same across treatments, except for stage 2 .

\subsection{Analysis}

In the individual decisions (all three stages of the control and stage 1 and 3 of the $\mathrm{M}$ - and U-treatments), we obviously used subjects' reported choices. In the group decisions (stage 2 for the M- and U-treatments), we assigned the choices of the subject's group to each subject. For the M-treatment in stage 2, we also had the information about the choices reported by each subject, because they were allowed to express disagreement with the group choice. Thirty-one percent of the majority group decisions revealed disagreement. Our conclusions did not depend on whether we used the group choices or the reported choices in the second stage of the M-treatment (see Online Appendix A).

We used probit models to study the likelihood of violations of stochastic dominance and multinomial probit models to study the likelihood of the four CC and CR patterns. Logit models, reported in Online Appendix B, gave similar results. We used clustered standard errors in the probit regressions. For the NTSD task, the dependent (binary) variable indicated whether or not the choice satisfied stochastic dominance. For the CC and the CR tasks, the dependent (categorical) variable described the choice pattern (SS, SR, RS, or RR). 
We used the dummy variables majority, unanimity, stage2, and stage 3 to code stages and treatments. The main effects stage 2 and stage 3 captured the effect of learning. Our main independent variables represented the interaction terms of the treatments with the stages. The terms majority*stage 2 and unanimity*stage 2 identified the full effect of group decision making (both aggregation and communication effects). The terms majority*stage 3 and unanimity*stage 3 captured the changes in preferences after the group stage and provided a first method to estimate communication effects.

As explained before, the second method to disentangle aggregation and communication effects used the individual choices (of stage 1 for the $\mathrm{M}$ - and U-treatments and stages 1 and 2 for the control treatment) to simulate aggregate choices. For the majority rule, as each session consisted of three subjects, we could in each case simulate the majority group choice. These simulated group choices captured the pure aggregation effects. The difference between the simulated and the actual group choices provided an estimate of communication effects. The majority preference is also the most plausible benchmark for the U-treatment. A deviation from the majority choice then can only occur if some group members were willing to change their minds, and there must then have been communication effects. The analysis of the simulated and the group choices was done the same way as the analysis of the individual and the group choices, which was described above, except that we excluded stage 3 (which would give no useful insights) and thus used fewer data points.

Finally, we also recorded and studied the group discussions. In nearly $40 \%$ of the groups, arguments based on stochastic dominance were used (without using this term though). The dummy variable dominance_discussion identified the members of such groups.

\section{Results}

\subsection{NTSD tasks}

Figure 1 displays the proportion of choices satisfying stochastic dominance, for the actual choices (panel A) and when individual choices are replaced by the simulated choices (panel B). Panel A shows that only a minority of subjects chose the dominant lottery in the first stage. In the control treatment, the proportion of choices satisfying stochastic dominance increased from around $40 \%$ in stage 1 to around $50 \%$ in stage 2 to slightly below $60 \%$ in stage 3 , suggesting modest learning. In the M- and Utreatments, we see a faster increase in the second stage, due to aggregation and communication effects. The comparison of the group choices with the simulated choices (panel B) confirms that even though subjects of all treatments better identify dominant lotteries as the experiment progresses, this improvement is faster in the Mand U-treatments than in the control treatment.

Table 8 reports the results of the probit regressions. The first column, which reports the results for the actual choices, shows that the use of stochastic dominance arguments in the group discussion was crucial. Groups in which no stochastic dominance arguments were used did not differ from the control treatment. However, there were strong group effects in stages 2 and 3 for groups that did talk about stochastic dominance (captured by the three-way interaction terms between stages, treatments and dominance_discussion). Hence, a subject who used stochastic dominance arguments 
A Individual vs. group choice

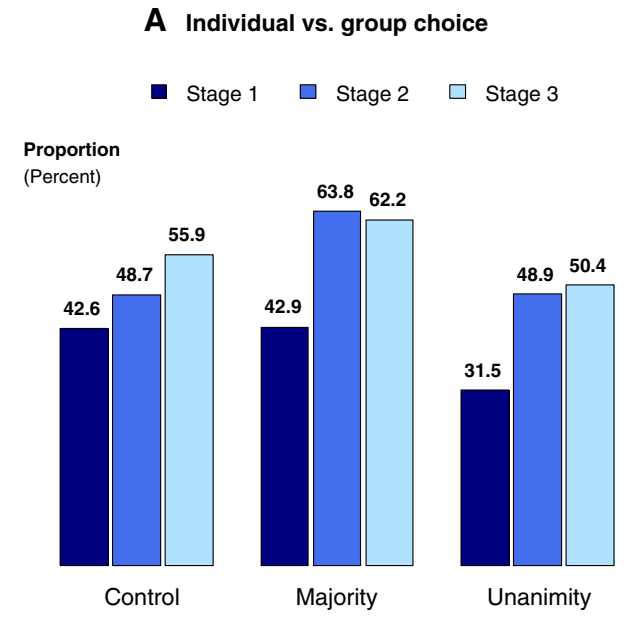

B Simulated vs. group choice

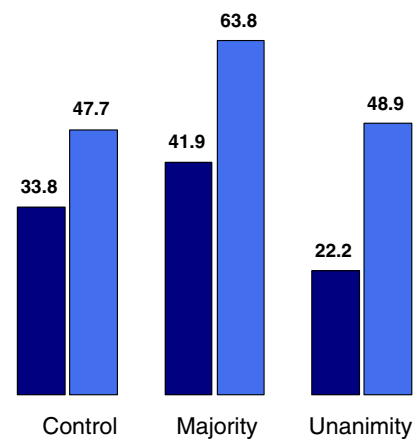

Fig. 1 Proportion of choices satisfying stochastic dominance across treatments and stages

strongly affected not only his group's choices in stage 2 but also the individual choices of his fellow group members in stage 3 , indicating communication effects. In the Mtreatment, the significant interaction term dominance_discussion*majority captures the difference in satisfaction of stochastic dominance in stage 1 between subjects who talked about stochastic dominance in stage 2 and those who did not.

The comparison of group choices with simulated choices confirmed that communication effects played a role in both the M-treatment and the U-treatment. Once aggregation effects were ruled out, groups that talked about stochastic dominance were still more likely to choose the dominant lotteries in all stages than groups that did not talk about stochastic dominance. The three-way interactions between majority, dominance_discussion, and stage2 and between unanimity, dominance_discussion, and stage 2 were significant, showing that the choices of groups that talked about stochastic dominance were affected by communication effects beyond pure aggregation effects. Majority and unanimity seemed to have fostered discussions, which increased subjects' rationality. The importance of avoiding biases and increasing rationality has often been emphasized (Viscusi 1995, p. 108) and our analysis shows that group decision making can contribute here. 
Table 8 Probit regressions for the NTSD tasks

\begin{tabular}{lllll}
\hline & \multicolumn{2}{l}{ Group vs. individual choices } & \multicolumn{2}{l}{ Group vs. simulated choices } \\
\hline stage2 & .06 & $(.04)$ & $.14 * *$ & $(.07)$ \\
stage3 & $.13 * *$ & $(.06)$ & & \\
majority & -.09 & $(.09)$ & -.05 & $(.17)$ \\
unanimity & $-.17 *$ & $(.10)$ & -.17 & $(.17)$ \\
stage2*majority & .02 & $(.07)$ & .01 & $(.12)$ \\
stage2*unanimity & -.16 & $(.10)$ & -.14 & $(.14)$ \\
stage3*majority & -.02 & $(.08)$ & & \\
stage3*unanimity & -.11 & $(.09)$ & & \\
majority*dominance_discussion & $.24 * *$ & $(.11)$ & $.34 *$ & $(.18)$ \\
unanimity*dominance_discussion & .12 & $(.12)$ & .08 & $(.17)$ \\
stage2*majority*dominance_discussion & $.44 * * *$ & $(.14)$ & $.50 * *$ & $(.24)$ \\
stage2*unanimity*dominance_discussion & $.84 * * *$ & $(.15)$ & $.89 * * *$ & $(.21)$ \\
stage3*majority*dominance_discussion & $.34 * * *$ & $(.13)$ & & \\
stage3*unanimity*dominance_discussion & $.47 * * *$ & $(.14)$ & & \\
No. of observations & 2340 & & 520 & \\
Wald chi2 & 149.69 & & 74.69 & \\
$p$-value & 0.00 & & 0.00 & \\
\hline
\end{tabular}

Reported numbers are the marginal effects at the means of covariates, followed by significance and clustered standard errors between brackets. The standard errors in the left column are clustered at the individual level, ${ }^{\mathrm{a}}$ and those in the right column are clustered at the group level

*significant at $10 \%$ (two-sided test)

**significant at $5 \%$ (two-sided test)

***significant at $1 \%$ (two-sided test)

${ }^{\text {a }}$ Clustering at the group level did not change the results (see Online Appendix Table A1)

\subsection{CC tasks}

Neither the majority nor the unanimity group rule led to more EU-consistent choices in the common consequence Allais paradoxes (Fig. 2). In the first stage, half of our subjects' choices were consistent with EU (32\% of the choice patterns were RR and $18 \%$ were SS). Surprisingly, the violations of EU were mainly of the RS type: $45 \%$ of the patterns were RS and only $5 \%$ of the empirically common SR. This finding does not confirm the certainty effect. The low occurrence of the SR pattern led to estimation problems and we excluded it from the analysis reported below. Keeping the SR pattern whenever possible gave similar results as those reported next (see Online Appendix C).

The proportion of EU violations slightly dropped in the second stage, but this held for all treatments and it disappeared in the third stage. The control and the M-treatment are very similar. In the U-treatment, there was a more pronounced increase in the proportion of RR choices, but, again, the effect did not last. Several studies have found that risk aversion is negatively related to cognitive ability (Frederick 2005; Dohmen et al. 2010, 2011). Hence the unanimity rule may also lead to more rationality in the $\mathrm{CC}$ task. This is 


\section{A Twice safe (SS) \\ Individual vs. group choice}

- Stage $1 \square$ Stage $2 \square$ Stage 3
B Twice safe (SS)

Simulated vs. group choice

\section{Proportion}

(Percent)

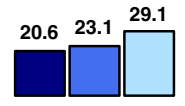

Control

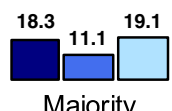

Majority

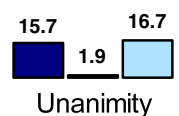

Unanimity

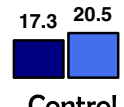

Control

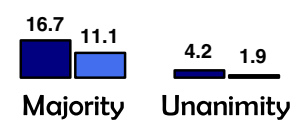

C First risky then safe (RS) Individual vs. group choice

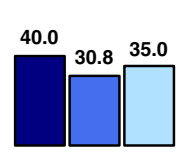

Control

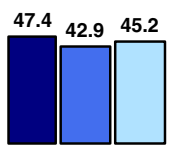

Majority

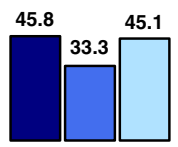

Unanimity

E Twice risky (RR)

Individual vs. group choice

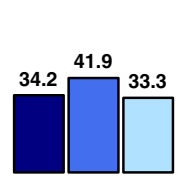

Control

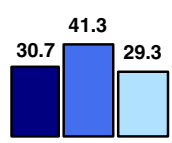

Majority

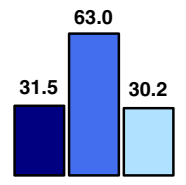

Unanimity

D First risky then safe (RS) Simulated vs. group choice

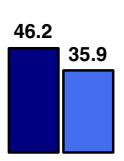

Control

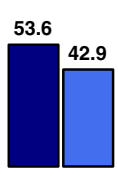

Majority
58.3

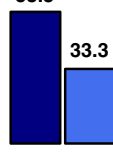

Unanimity

Fig. 2 Proportion of choices in the Allais common consequence tasks per treatment and stage

consistent with Keck et al.'s (2014) finding that groups are closer to EU (ambiguity neutrality) than individuals. However, the effect did not last.

The literature that compares risk attitudes between groups and individuals gives mixed results. Rockenbach et al. (2007) and Viscusi et al. (2011) found that groups were more risk seeking than individuals. On the other hand, Masclet et al. (2009) found that groups were more risk averse than individuals. Adams and Ferreira (2010) found that groups made decisions closer to risk neutrality than individuals do.

Table 9 shows the results of the multinomial probit regressions. Subjects became more risk averse during the experiment as indicated by the positive coefficient of stage 3 in the SS choices. Groups were more risk seeking than individuals: in stage 2, the prevalence of the SS pattern was less in the M- and U-treatments than in the control treatment. The RR pattern was also more common in the U-treatment than in the control group in stage 2. However, the two-way interactions in stage 3 (stage $3 *$ majority and stage $3 *$ unanimity) were not significant and there was no evidence of communication effects. When comparing group choices with simulated choices, the treatment effects on the 
Table 9 Multinomial probit regressions for the CC tasks

\begin{tabular}{|c|c|c|c|c|c|c|}
\hline & \multicolumn{3}{|c|}{ Group vs. individual choices } & \multicolumn{3}{|c|}{ Group vs. simulated choices } \\
\hline Choice pattern & $\mathrm{SS}$ & RR & RS & SS & RR & RS \\
\hline \multirow[t]{2}{*}{ stage 2} & .02 & .08 & $-.10 *$ & .02 & .12 & -.13 \\
\hline & $(.02)$ & $(.05)$ & $(.05)$ & $(.04)$ & $(.10)$ & $(.11)$ \\
\hline \multirow[t]{2}{*}{ stage3 } & $.06 * *$ & -.01 & -.06 & & & \\
\hline & $(.03)$ & $(.06)$ & $(.06)$ & & & \\
\hline \multirow[t]{2}{*}{ majority } & -.02 & -.04 & .07 & -.01 & -.03 & .04 \\
\hline & $(.06)$ & $(.07)$ & $(.07)$ & $(.08)$ & $(.12)$ & $(.12)$ \\
\hline \multirow[t]{2}{*}{ unanimity } & -.04 & -.02 & .07 & -.15 & .03 & .12 \\
\hline & $(.06)$ & $(.07)$ & $(.07)$ & $(.10)$ & $(.13)$ & $(.12)$ \\
\hline \multirow[t]{2}{*}{ stage $2 *$ majority } & $-.10 * *$ & .03 & .07 & -.06 & .02 & .04 \\
\hline & $(.05)$ & $(.07)$ & $(.08)$ & $(.06)$ & $(.13)$ & (.14) \\
\hline \multirow[t]{2}{*}{ stage $2 *$ unanimity } & $-.29 * * *$ & $.25 * * *$ & .04 & -.08 & .18 & -.10 \\
\hline & $(.07)$ & $(.07)$ & $(.08)$ & $(.05)$ & $(.12)$ & $(.13)$ \\
\hline \multirow[t]{2}{*}{ stage $3 *$ majority } & -.05 & .00 & .05 & & & \\
\hline & $(.04)$ & $(.07)$ & $(.07)$ & & & \\
\hline \multirow[t]{2}{*}{ stage $3 *$ unanimity } & -.05 & -.00 & .05 & & & \\
\hline & $(.06)$ & $(.08)$ & $(.08)$ & & & \\
\hline No. of observations & \multicolumn{3}{|c|}{1481} & \multicolumn{3}{|c|}{350} \\
\hline Wald chi2 & \multicolumn{3}{|c|}{86.83} & \multicolumn{3}{|c|}{32.94} \\
\hline p-value & \multicolumn{3}{|c|}{0.00} & \multicolumn{3}{|c|}{0.00} \\
\hline
\end{tabular}

Reported numbers are the marginal effects at the means of covariates, followed by significance and clustered standard errors between brackets. The standard errors in the left three columns are clustered at the individual level, and those in the right three columns are clustered at the group level. Missing choices and SR patterns are excluded

* significant at $10 \%$ (two-sided test)

** significant at $5 \%$ (two-sided test)

*** significant at $1 \%$ (two-sided test)

SS and RR patterns at stage 2 disappeared, confirming the absence of communication effects. The tendency to make riskier group decisions was thus mainly due to aggregation effects.

\subsection{CR tasks}

In the CR tasks (Fig. 3), we again found that about half of the subjects satisfied EU in the first stage (29\% SS pattern, 22\% RR pattern). This time we found the usual SR violation of EU (41\%). We do not report the results about the infrequent RS pattern, because it led to estimation problems in one of the regressions. Keeping the RS pattern did not affect the results of the other regressions as can be seen in Online Appendix C.

As in the $\mathrm{CC}$ tasks, group choices tended to be more risk seeking than individual choices. However, this time the shift was predominantly from SS to the EUinconsistent SR pattern and less so to the EU-consistent RR pattern.

The multinomial probit regressions in Table 10 confirmed that the $\mathrm{M}$ - and $\mathrm{U}$ treatments decreased the number of SS patterns and increased the number of SR patterns. These effects did not last in stage 3, suggesting that they were aggregation effects. This suggestion was confirmed by the comparison between the group choices and the simulated choices, in which these effects disappeared: the prevalence of the SS and SR patterns in the actual group choices (stage 2 of the M- and U-treatments) did not differ from the prevalence of these patterns in the simulated choices. 

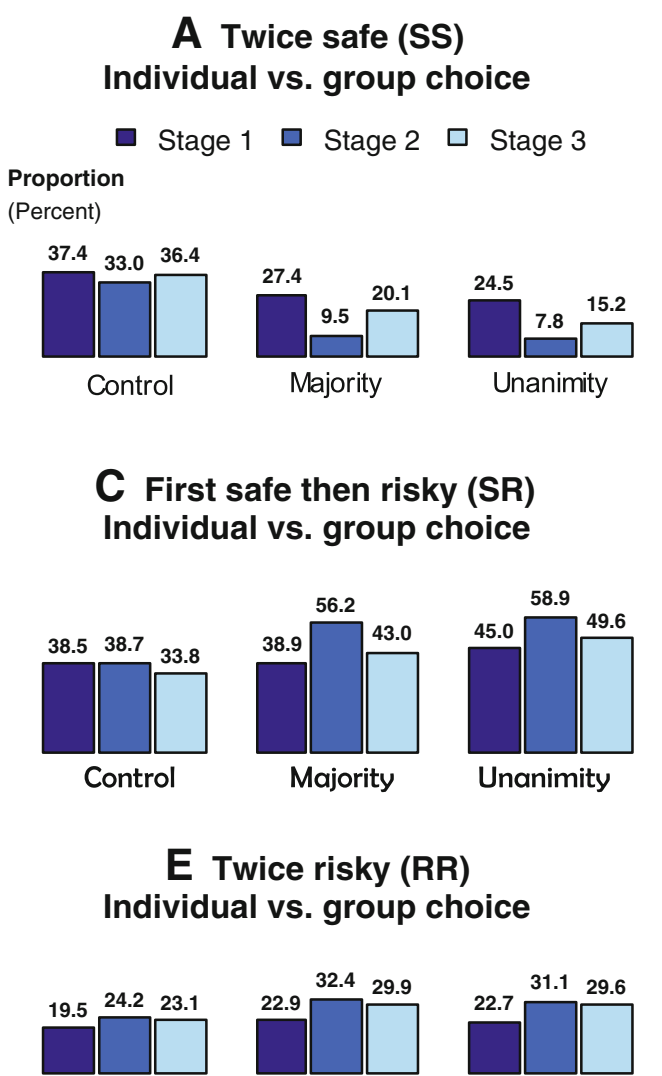

Control

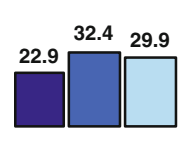

Majority

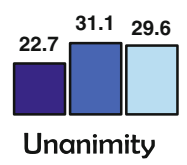

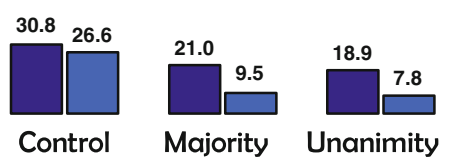

D First safe then risky (SR)
Simulated vs. group choice

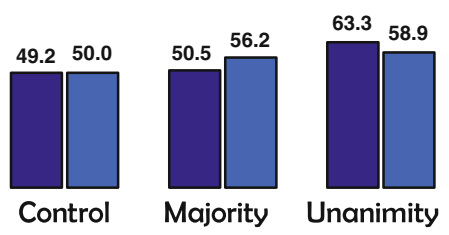

\section{F Twice risky (RR) Simulated vs. group choice}

Fig. 3 Proportion of choices in the Allais common ratio tasks per treatment and stage

In the regression comparing groups with simulated choices, there were marginally more RR-choices in stage 2 than in stage 1 for treatment U, suggesting that communication increased risk seeking. This was not observed in the regression comparing groups with individual choices. This result indicates that aggregation effects and communication effects had opposite effects on the proportion of RR choices. Communication effects led to an increase in RR choices, whereas aggregation effects reduced them. These effects could not be observed in the actual choices because the aggregation effects and communication effects were close in magnitude and cancelled out. It shows the added value of analyzing the simulated choices. The finding that communication effects led to more risk seeking suggests that individual choices may be too risk averse and (some) more risk seeking may be rational. On the other hand, the effect was only modest and unlike the findings on NTSD, it did not persist in the third stage.

\subsection{Additional analysis}

We recorded the decision time at each stage. Table 11 reports the results of a linear regression of decision times on treatments and on stages. The M- and U-treatments took 
Table 10 Multinomial probit regressions for the CR tasks

\begin{tabular}{|c|c|c|c|c|c|c|}
\hline & \multicolumn{3}{|c|}{ Group vs. individual choices } & \multicolumn{3}{|c|}{ Group vs. simulated choices } \\
\hline Choice pattern & $\mathrm{SS}$ & RR & SR & SS & RR & SR \\
\hline \multirow[t]{2}{*}{ stage 2} & -.04 & .05 & -.01 & -.03 & .03 & -.00 \\
\hline & $(.03)$ & $(.04)$ & $(.06)$ & $(.04)$ & $(.06)$ & $(.09)$ \\
\hline \multirow[t]{2}{*}{ stage3 } & -.00 & .05 & -.05 & & & \\
\hline & $(.03)$ & $(.04)$ & $(.05)$ & & & \\
\hline \multirow[t]{2}{*}{ majority } & -.07 & .05 & .02 & -.06 & .03 & .04 \\
\hline & $(.06)$ & $(.07)$ & $(.08)$ & $(.09)$ & $(.11)$ & $(.13)$ \\
\hline \multirow[t]{2}{*}{ unanimity } & $-.10 *$ & .03 & .07 & -.09 & -.07 & .16 \\
\hline & $(.06)$ & $(.08)$ & $(.08)$ & $(.09)$ & $(.11)$ & $(.13)$ \\
\hline \multirow[t]{2}{*}{ stage $2 *$ majority } & $-.19 * * *$ & .03 & $16^{* *}$ & -.10 & .06 & .05 \\
\hline & $(.06)$ & $(.06)$ & $(.08)$ & $(.08)$ & $(.08)$ & $(.12)$ \\
\hline \multirow[t]{2}{*}{ stage $2 *$ unanimity } & $-.19 * * *$ & .04 & $.14^{*}$ & -.11 & $.15^{*}$ & -.04 \\
\hline & $(.06)$ & $(.07)$ & $(.08)$ & $(.09)$ & $(.08)$ & $(.12)$ \\
\hline \multirow[t]{2}{*}{ stage $3 *$ majority } & -.08 & .01 & .07 & & & \\
\hline & $(.06)$ & $(.06)$ & $(.08)$ & & & \\
\hline \multirow[t]{2}{*}{ stage $3 *$ unanimity } & $-.10^{*}$ & .02 & .09 & & & \\
\hline & $(.06)$ & $(.06)$ & $(.07)$ & & & \\
\hline No. of observations & \multicolumn{3}{|c|}{2202} & \multicolumn{3}{|c|}{505} \\
\hline Wald chi2 & \multicolumn{3}{|c|}{53.82} & \multicolumn{3}{|c|}{24.70} \\
\hline p-value & \multicolumn{3}{|c|}{0.00} & \multicolumn{3}{|c|}{0.00} \\
\hline
\end{tabular}

Reported numbers are the marginal effects at the means of covariates, followed by significance and clustered standard errors between brackets. The standard errors in the left three columns are clustered at the individual level, and those in the right three columns are clustered at the group level. Missing choices and RS patterns are excluded

* significant at $10 \%$ (two-sided test)

** significant at $5 \%$ (two-sided test)

*** significant at $1 \%$ (two-sided test)

more time than the control treatment in stage 2, but they did not differ from each other $(p=0.20)$. Response time decreased for the second and third stages of the control treatment and we also observed that the response time was less in the third stage than in the first stage in both the majority and the unanimity treatments.

Table 11 Linear regression on decision time

\begin{tabular}{lc}
\hline stage2 & $-1.77 *(0.96)$ \\
stage3 & $-2.73 * * *(0.96)$ \\
majority & $0.05(0.86)$ \\
unanimity & $0.50(0.89)$ \\
stage2*majority & $3.72 * * *(1.22)$ \\
stage $2 *$ unanimity & $5.16 * * *(1.26)$ \\
stage3*majority & $-0.27(1.22)$ \\
stage $3 *$ unanimity & $-0.57(1.26)$ \\
\hline
\end{tabular}

Reported numbers are regression coefficients, followed by significance and standard errors. The unit of the dependent variable is minute

* significant at 10\% (two-sided test)

** significant at 5\% (two-sided test)

*** significant at $1 \%$ (two-sided test) 


\section{Conclusion}

We disentangled communication effects and aggregation effects in group decisions. This allowed us to analyze the effects of unanimity and majority rules on intellective and judgmental tasks under risk. Our results show that:

a) Both aggregation effects and communication effects occurred, but these effects were stronger and occurred more often under the unanimity rule.

b) Aggregation effects were mixed and did not always lead to more rational choices. Aggregation effects reduced violations of stochastic dominance, but they also reduced EU-consistent patterns in Allais' common ratio tasks, and they changed the distribution of EU-consistent choice patterns in Allais' common consequence task without affecting the overall proportion of EU-consistent choice patterns.

c) Communication effects favored the justifiable (rational) choices and had more impact in intellective tasks than in judgmental tasks. When there was a clear argument for a particular choice, such as in the nontransparent stochastic dominance tasks, then communication effects could strongly increase the proportion of such choices in the group decisions. Communication effects led to more risk seeking in the common ratio tasks (with marginal significance), but not in the common consequence tasks. Communication effects increased rationality but they also increased decision times.

The separation of communication and aggregation effects introduced in this paper sheds new light on the pros and cons of group decision rules and on their differences with individual decisions. In particular, we can test whether these rules increase the rationality of group decisions, and have a lasting impact on individual decisions after the group process is over. Our results show that communication effects play an important role in group decisions.

Acknowledgments Gary Charness, Enrico Diecidue, Yoram Halevy, the editor W. Kip Viscusi, and an anonymous reviewer gave helpful suggestions. The research of Aurélien Baillon was made possible by a grant from the Netherlands Organization for Scientific Research (NWO).

Open Access This article is distributed under the terms of the Creative Commons Attribution 4.0 International License (http://creativecommons.org/licenses/by/4.0/), which permits unrestricted use, distribution, and reproduction in any medium, provided you give appropriate credit to the original author(s) and the source, provide a link to the Creative Commons license, and indicate if changes were made.

\section{References}

Adams, R., \& Ferreira, D. (2010). Moderation in groups: Evidence from betting on ice break-ups in Alaska. The Review of Economic Studies, 77(3), 882-913.

Allais, M. (1953). Le comportement de l'homme rationnel devant le risque: Critique des postulats et axiomes de l'ecole Americaine. Econometrica, 21(4), 503-546.

Bateman, I., \& Munro, A. (2005). An experiment on risky choice amongst households. The Economic Journal, 115(502), C176-C189.

Blavatskyy, P. R. (2013). The reverse Allais paradox. Economics Letters, 119(1), 60-64.

Bone, J., Hey, J., \& Suckling, J. (1999). Are groups more (or less) consistent than individuals? Journal of Risk and Uncertainty, 18(1), 63-81. 
Brunette, M., Cabantous, L., \& Couture, S. (2015). Are individuals more risk and ambiguity averse in a group environment or alone? Results from an experimental study. Theory and Decision, 78(3), 357-376.

Charness, G., Karni, E., \& Levin, D. (2007). Individual and group decision making under risk: An experimental study of Bayesian updating and violations of first-order stochastic dominance. Journal of Risk and Uncertainty, 35(2), 129-148.

Charness, G., \& Sutter, M. (2012). Groups make better self-interested decisions. The Journal of Economic Perspectives, 26(3), 157-176.

Dasgupta, P., \& Maskin, E. (2008). On the robustness of majority rule. Journal of the European Economic Association, 6(5), 949-973.

Davis, J. H. (1973). Group decision and social interaction: A theory of social decision schemes. Psychological Review, 80(2), 97-125.

Davis, J. H. (1992). Some compelling intuitions about group consensus decisions, theoretical and empirical research, and interpersonal aggregation phenomena: Selected examples 1950-1990. Organizational Behavior and Human Decision Processes, 52(1), 3-38.

Dohmen, T., Falk, A., Huffman, D., \& Sunde, U. (2010). Are risk aversion and impatience related to cognitive ability? American Economic Review, 100(3), 1238-1260.

Dohmen, T., Falk, A., Huffman, D., Sunde, U., Schupp, J., \& Wagner, G. G. (2011). Individual risk attitudes: Measurement, determinants, and behavioral consequences. Journal of the European Economic Association, 9(3), 522-550.

Evans, D. A. (1997). The role of markets in reducing expected utility violations. Journal of Political Economy, $105,622-636$.

Feddersen, T., \& Pesendorfer, W. (1998). Convicting the innocent: The inferiority of unanimous jury verdicts under strategic voting. The American Political Science Review, 92(1), 23-35.

Fishburn, P., \& Wakker, P. P. (1995). The invention of the independence condition for preferences. Management Science, 41(7), 1130-1144.

Frederick, S. (2005). Cognitive reflection and decision making. The Journal of Economic Perspectives, 19(4), $25-42$.

Goeree, J. K., \& Yariv, L. (2011). An experimental study of collective deliberation. Econometrica, 79(3), 893921.

Huber, J., Viscusi, W. K., \& Bell, J. (2008). Reference dependence in iterative choices. Organizational Behavior and Human Decision Processes, 106, 143-152.

Huck, S., \& Müller, W. (2012). Allais for all: Revisiting the paradox in a large representative sample. Journal of Risk and Uncertainty, 44(3), 261-293.

Kahneman, D., \& Tversky, A. (1979). Prospect theory: An analysis of decision under risk. Econometrica, 47(2), 263-291.

Kameda, T. (1991). Procedural influence in small-group decision making: Deliberation style and assigned decision rule. Journal of Personality and Social Psychology, 61(2), 245-256.

Keck, S., Diecidue, E., \& Budescu, D. V. (2014). Group decisions under ambiguity: Convergence to neutrality. Journal of Economic Behavior \& Organization, 103, 60-71.

Kerr, N. L., MacCoun, R. J., \& Kramer, G. P. (1996). Bias in judgment: Comparing individuals and groups. Psychological Review, 103(4), 687-719.

Kerr, N. L., \& Tindale, R. S. (2004). Group performance and decision making. Annual Review of Psychology, 55(1), 623-655.

Kerr, N. L., \& Tindale, R. S. (2011). Group-based forecasting? A social psychological analysis. International Journal of Forecasting, 27(1), $14-40$.

Kugler, T., Kausel, E. E., \& Kocher, M. G. (2012). Are groups more rational than individuals? A review of interactive decision making in groups. Wiley Interdisciplinary Reviews: Cognitive Science, 3(4), 471-482.

Laughlin, P. R., \& Ellis, A. L. (1986). Demonstrability and social combination processes on mathematical intellective tasks. Journal of Experimental Social Psychology, 22(3), 177-189.

Loomes, G. (1988). Further evidence of the impact of regret and disappointment in choice under uncertainty. Economica, 55(217), 47-62.

Maciejovsky, B., Sutter, M., Budescu, D. V., \& Bernau, P. (2013). Teams make you smarter: How exposure to teams improves individual decisions in probability and reasoning tasks. Management Science, 59(6), 1255-1270.

Masclet, D., Colombier, N., Denant-Boemont, L., \& Lohéac, Y. (2009). Group and individual risk preferences: A lottery-choice experiment with self-employed and salaried workers. Journal of Economic Behavior \& Organization, 70(3), 470-484.

Messner, M., \& Polborn, M. K. (2004). Voting on majority rules. The Review of Economic Studies, 71(1), 115-132. 
Miller, C. E. (1985). Group decision making under majority and unanimity decision rules. Social Psychology Quarterly, 48(1), 51-61.

Nemeth, C. (1977). Interactions between jurors as a function of majority vs. unanimity decision rules. Journal of Applied Social Psychology, 7, 38-56.

Ohtsubo, Y., Miller, C. E., Hayashi, N., \& Masuchi, A. (2004). Effects of group decision rules on decisions involving continuous alternatives: The unanimity rule and extreme decisions in mock civil juries. Journal of Experimental Social Psychology, 40(3), 320-331.

Rockenbach, B., Sadrieh, A., \& Mathauschek, B. (2007). Teams take the better risks. Journal of Economic Behavior \& Organization, 63(3), 412-422.

Savage, L. J. (1954). The Foundations of Statistics. New York: Wiley.

Starmer, C. (1992). Testing new theories of choice under uncertainty using the common consequence effect. The Review of Economic Studies, 59(4), 813-830.

Starmer, C. (2000). Developments in non-expected utility theory: The hunt for a descriptive theory of choice under risk. Journal of Economic Literature, 38(2), 332-382.

Stasson, M. F., Kameda, T., Parks, C. D., Zimmerman, S. K., \& Davis, J. H. (1991). Effects of assigned group consensus requirement on group problem solving and group members' learning. Social Psychology Quarterly, 54(1), 25-35.

Tversky, A., \& Kahneman, D. (1986). Rational choice and the framing of decisions. The Journal of Business, 59(4), S251-S278.

Van de Kuilen, G., \& Wakker, P. P. (2006). Learning in the Allais paradox. Journal of Risk and Uncertainty, 33(3), 155-164.

Viscusi, W. K. (1989). Prospective reference theory: Toward an explanantion of the paradoxes. Journal of Risk and Uncertainty, 2, 235-264.

Viscusi, W. K. (1995). Government action, biases in risk perception, and insurance decisions. Geneva Papers in Risk and Insurance Theory, 20, 93-110.

Viscusi, W. K., Phillips, O. R., \& Kroll, S. (2011). Risky investment decisions: How are individuals influenced by their groups? Journal of Risk and Uncertainty, 43(2), 81-106.

Wu, G., Zhang, J., \& Abdellaoui, M. (2005). Testing prospect theories using probability tradeoff consistency. Journal of Risk and Uncertainty, 30(2), 107-131. 